\title{
A study on the thermophysiological and tactile comfort properties of silk/lyocell blended fabrics
}

Mariyam Adnan ${ }^{1}$, Jeyakodi Moses ${ }^{2}$

\author{
${ }^{1}$ Department of Apparel and Fashion Design, PSG College of Technology, 641004, Peelamedu, Coimbatore, India. \\ ${ }^{2}$ Department of Applied Science, PSG College of Technology, 641004, Peelamedu, Coimbatore, India. \\ e-mail: mariyam.ag@gmail.com,jj_moses2k2@yahoo.co.in
}

\begin{abstract}
Certain investigations on the thermophysiological and tactile comfort properties of silk/lyocell blended fabrics have been carried out. A series of yarns were produced as 100\% silk (S 100), 75\% silk and 25\% lyocell (S/L 75:25), 50\% silk and 50\% lyocell (S/L 50:50), 25\% silk and 75\% lyocell (S/L 25:75) and 100\% lyocell (L 100) and converted to woven fabrics keeping the same fabric set. FTIR study on silk, lyocell and silk/lyocell blended fabrics show the characteristic functional groups for the respective fabrics. The effects of blend compositions on thermophysiological and tactile comfort properties were examined and the results show that thermal resistance of the fabrics containing silk has a higher value in comparison with lyocell-rich blends. Water vapour permeability, absorbency and wickability for lyocell and lyocell-rich blends are found to be superior as compared to $100 \%$ silk fabrics. With respect to drape, bending length and crease recovery the lyocell rich fabrics are good in comparison with $100 \%$ silk fabrics. The results are discussed using one way ANOVA with 5\% significant level.
\end{abstract}

Keywords: silk, lyocell, blending, comfort, eco-friendly.

\section{INTRODUCTION}

Clothing comfort is considered as a fundamental need for consumers and is defined as a pleasant state arising out of physiological, psychological and physical harmony between a human being and the environment. The literature generally classifies clothing comfort into three broad categories namely, aesthetic comfort, thermo-physiological comfort and tactile comfort. Aesthetic appeal or psychological comfort is mainly based on subjective feelings and fashion trends that influence customer preferences. On the other hand, thermophysiological comfort relates to the ability of the fabric to maintain thermal equilibrium between the human body and the environment. Thermal, moisture and air resistance properties of the clothing material collectively contribute to the state of thermophysiological comfort of the wearer. The tactile comfort is related to the feel of the fabric against the human body and is an intrinsic and essential performance requirement in clothing. Numerous systems have been developed to test the fabric tactile properties such as bending and drape [1,2].

Silk fabrics are priced for their vanity, versatility, wearability and comfort. It absorbs moisture, which makes it cool in summer and warm in winter. It retains the shape, drapes well and sparkles with a dazzling lustre. Silk is extremely costly, in spite of all the wonderful properties it possesses. The demand of blended silk fabric is expected day by day due to the constant increase in price of silk fabric. This has made the conjugation of silk and synthetic fabrics more popular in the market [3].

Lyocell fibers may be defined as cellulosic fibers that are produced by regenerating cellulose into fiber form out of a solution in N-methylmorpholine-N-oxide (NMMO) [4]. Solvent spun lyocell fibers consist of crystalline cellulose-II and amorphous cellulose, and have a higher degree of crystallinity $(80 \%)$ in comparison with other regenerated cellulosic fibers, such as modal (49\%) and viscose (41\%) [5]. It is $100 \%$ natural in origin, as it is made from wood pulp, and is fully biodegradable. Lyocell fibers are mostly used for apparel fabrics but it has been shown that, due to the fibrillating property very interesting nonwoven fabrics can also be made as well $[6,7]$. Fabrics made of $100 \%$ lyocell or blends have a luxurious and silky hand with vibrant colours. Unlike the previous generation of cellulosic fibers, the new generation of lyocell has tenacity that withstands rigorous processing. Across the fashion spectrum, it has been embraced by well-known designers and retailers. Lyocell fiber blends well with other natural and synthetic fibers such as cotton, polyester, lycra or wool adding comfort and performance $[8,9,10]$. 
Blending of silk with lyocell has many advantages over blending of silk with cotton or any other synthetic fibers. Lyocell is more versatile and uniform than cotton as it is a manmade fiber [11]. It scores over synthetics because it is a biodegradable fiber and reduces the burdens to ecosystem [4]. Lyocell has similar appearance, moisture content, strength, and luster to that of silk. Lyocell has a functional group $(-\mathrm{OH})$ similar to that of cotton, whereas silk contains different functional groups, such as- $\mathrm{COOH},-\mathrm{NH}_{2},-\mathrm{OH},-\mathrm{C}_{6} \mathrm{H}_{5} \mathrm{OH}$, that are highly useful when they are involved in chemical processing and subsequent end use products [9]. The cost of lyocell is less than $1 / 3^{\text {rd }}$ of silk. It has a dry strength higher than other cellulosics, approaching that of polyester. It also retains $85 \%$ of its strength when wet.

Although considerable research work has been carried out to study the viability of silk and lyocell with different yarns such as polyester and cotton for clothing application, very little published work is available on the use of silk/ lyocell blended fabrics. The principal objective of this study is to develop silk/lyocell blended fabrics comprising $100 \%$ silk, $75 \%$ silk and $25 \%$ lyocell, $50 \%$ silk and 50\% lyocell, $25 \%$ silk and $75 \%$ lyocell, and $100 \%$ lyocell and evaluation of their comfort properties. This study mainly focuses on the comfort characteristics and explores the possibilities of silk and lyocell blended fabrics for various apparel products so that even a common person can enjoy the unique richness of silk with excellent softness of lyocell.

\section{MATERIALS AND METHODS}

\subsection{Materials}

Commercially available mulberry silk cut filaments were purchased from a mill in Bengaluru, Karnataka, India and lyocell fibers were purchased from a mill in Coimbatore, Tamil Nadu, India. Sodium hydroxide $(\mathrm{NaOH})$ and other chemicals mentioned elsewhere in this study were of AR grade. Table 1 gives the fiber properties.

Table 1: Properties of silk and lyocell fibers

\begin{tabular}{l|c|c}
\hline PROPERTIES & SILK & LYOCELL \\
\hline Fiber length $(\mathrm{mm})$ & 40 & 40 \\
\hline Fiber denier & 1.1 & 1.2 \\
\hline Tenacity (g/d) & 3.4 & 4.1 \\
\hline Elongation (\%) & 18 & 13 \\
\hline
\end{tabular}

\subsection{Blending of silk and lyocell fibers}

Sliver blending was carried out in a mill at Coimbatore, Tamil Nadu, India. A series of blended yarns containing silk/lyocell in the ratio of 75:25, 50:50 and 25:75 were manufactured in a spinning unit and they were used for the study. In addition to these blended yarns, a $100 \%$ spun silk yarn and a $100 \%$ lyocell yarn were also produced. The blends were processed to produce $60 \mathrm{~s} \mathrm{Ne}$ (9.84 tex) yarn. The yarn properties are given in Table 2.

Table 2: Properties of silk/lyocell blended yarns

\begin{tabular}{l|c|c|c|c|c}
\hline PROPERTIES & $\mathbf{1 0 0 \%}$ SILK & $\begin{array}{c}\mathbf{7 5 \%} \text { SILK AND } \\
\mathbf{2 5 \%} \text { LYOCELL }\end{array}$ & $\begin{array}{c}\mathbf{5 0 \%} \text { SILK AND } \\
\mathbf{5 0 \%} \text { LYOCELL }\end{array}$ & $\begin{array}{c}\mathbf{2 5 \%} \text { SILK AND } \\
\mathbf{7 5 \%} \text { LYOCELL }\end{array}$ & $\begin{array}{c}\mathbf{1 0 0 \%} \\
\text { LYOCELL }\end{array}$ \\
\hline Count $(\mathrm{Ne})$ & 60.4 & 58.8 & 60.8 & 59.2 & 60.2 \\
\hline $\mathrm{CV} \%$ & 1.5 & 1.55 & 1.60 & 1.5 & 1.6 \\
\hline $\mathrm{Rkm}(\mathrm{g} / \mathrm{tex})$ & 18.4 & 19.8 & 20.2 & 20.4 & 19.8 \\
\hline $\mathrm{U} \%$ & 14.5 & 15.2 & 15.5 & 16 & 14.8 \\
\hline Thin places $-50 \% / \mathrm{Km}$ & 8 & 10 & 12 & 13 & 10 \\
\hline Thick places +50\%/Km & 20 & 25 & 31 & 36 & 60 \\
\hline Neps + 200\%/Km & 60 & 62 & 70 & 90 & 120 \\
\hline Total imperfections/Km & 88 & 97 & 113 & 139 & 190 \\
\hline
\end{tabular}




\subsection{Weaving of silk/lyocell blended yarns}

The blended yarns were woven into fabrics with identical warp and weft set on conventional under pick looms. The fabric details with the code are given in Table 3.

Table 3: Properties of silk/lyocell blended fabrics

\begin{tabular}{c|c|c|c|c}
\hline FABRIC SAMPLE CODE & YARN USED FOR WEAVING & FABRIC WEIGHT $\mathbf{( g / \mathbf { m } ^ { 2 } )}$ & ENDS/CM & PICKS/CM \\
\hline S 100 & $100 \%$ silk & 70.1 & 30 & 25 \\
\hline S/L 75:25 & $75 \%$ silk and 25\% lyocell & 71.1 & 30 & 25 \\
\hline S/L 50:50 & $50 \%$ silk and 50\% lyocell & 71.5 & 30 & 25 \\
\hline S/L 25:75 & $25 \%$ silk and 75\% lyocell & 71.8 & 30 & 25 \\
\hline L 100 & $100 \%$ lyocell & 72.0 & 30 & 25 \\
\hline
\end{tabular}

\subsection{Characterization of silk and lyocell fabrics by FTIR analysis}

Fourier transform infrared spectra (FTIR) of S100, L100 and S/L 25:75 blended fabrics were recorded in the range of 400 - $4000 \mathrm{~cm}^{-1}$ using a Shimadzu FTIR spectrophotometer, at a resolution of $2 \mathrm{~cm}^{-1}$.

\subsection{Testing of thermophysiological comfort properties and tactile properties on silk/lyocell blended} fabrics

The thermophysiological comfort properties such as air permeability was tested by KES-F8-API air permeability tester using the ASTM D737-2004 method, thermal resistance was calculated using the Lees disc by the ASTM E96-00 method, water vapour permeability of the samples was studied with the SDL, Atlas M261 using the BS EN ISO 15496-2004 method, absorbency was evaluated as per BS 4554 and wickability was measured as per AATCC 197:2012. The tactile properties such as drape was calculated using the Cusick drape meter as per BSI 1990 standard, crease recovery was measured on a Shirley crease recovery tester as per ISO 2313 and bending length was evaluated using Cantilever bending tester as per BS 3356.

\subsection{Statistical Analysis}

Statistical analysis was carried out using one way Analysis of Variance (ANOVA) to test the significance of comfort properties between the silk/lyocell blend compositions. A value of $\mathrm{P}<0.05$ is considered to be statistically significant. Pearson's correlation coefficient was also performed to find out the relationship between air permeability and water vapour permeability in silk/lyocell blended fabrics. The value of ' $r$ ' between -1 and +1 is considered good for correlation.

\section{RESULTS AND DISCUSSION}

\subsection{Characterization of silk/lyocell blended fabrics by FTIR analysis}

FTIR spectra for representative samples asuch as $100 \%$ silk, silk/lyocell 25:75 and 100\% lyocell fabrics are shown in Figure 1. 


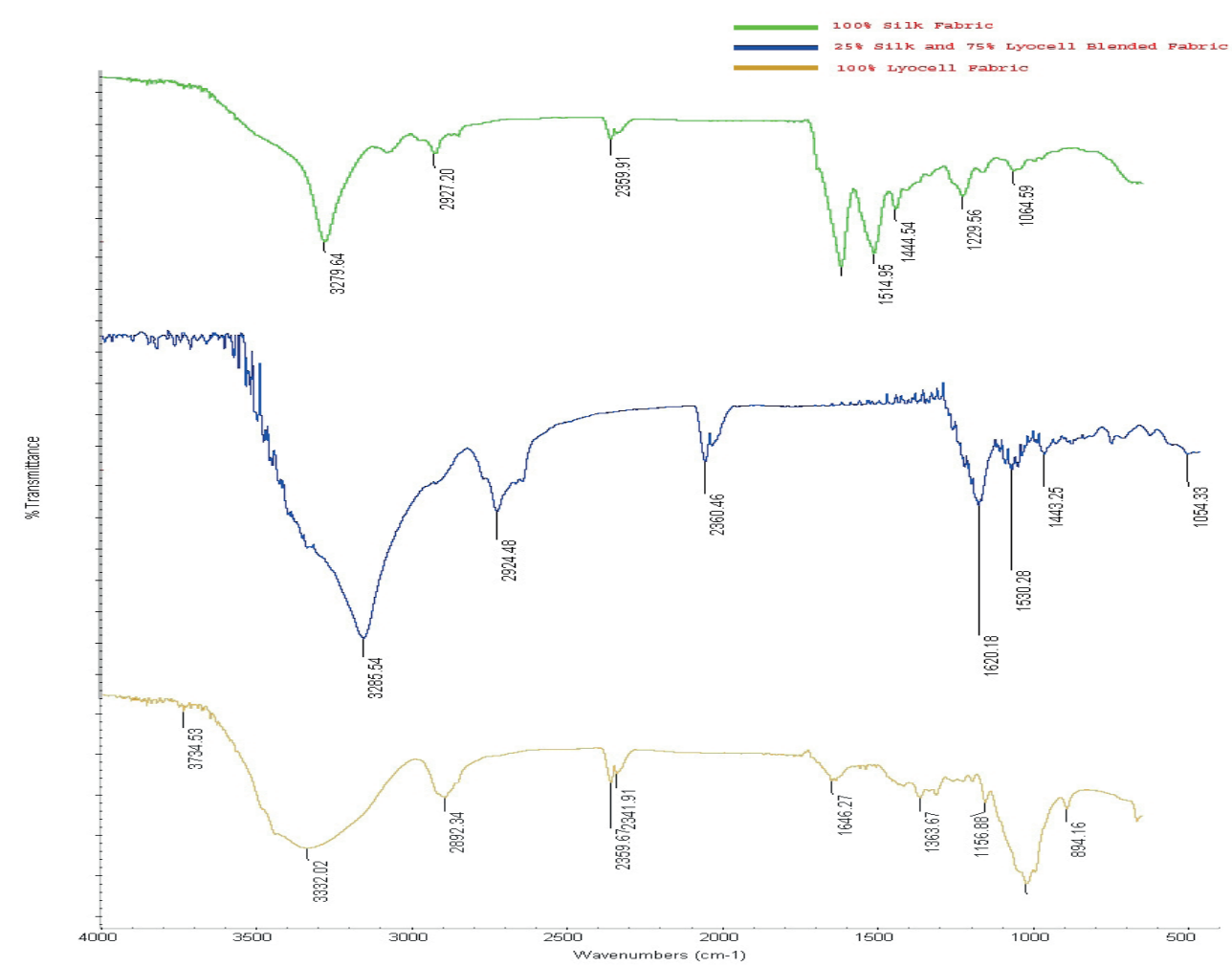

Figure 1: FTIR spectra of 100\% silk, silk/lyocell 25:75 and 100\% lyocell fabrics

With respect to S100, a distinct amino acid composition present in the fibroin of silk fabrics with the consequent difference in secondary structure of these proteins lead to characteristic infrared peaks. A broad amide A band $\left(3280 \mathrm{~cm}^{-1}\right)$, and amide I and II peaks at $1621 \mathrm{~cm}^{-1}$ and $1515 \mathrm{~cm}^{-1}$ is obtained. A further signature peak for fibroin at $1445 \mathrm{~cm}^{-1}$ and a much enhanced transmission at $1065 \mathrm{~cm}^{-1}$ is also observed. Th prominence of these features may be ascribed to the relatively high content of carboxylic acid and alkyl hydroxyl containing amino side chains in fibroin. Associated water and the raised hydroxyl content together also contribute to the broad transmittance at $3280 \mathrm{~cm}^{-1}$. The band at $10645 \mathrm{~cm}^{-1}$ is characteristic of -gly-gly-peptide backbone [12].

FTIR spectra for S/L 25:75 clearly show peaks at $3285 \mathrm{~cm}^{-1}$ which corresponds to the $-\mathrm{OH}$ stretching band of cellulose, peak at $2925 \mathrm{~cm}^{-1}$ which corresponds to the $\mathrm{C}-\mathrm{H}$ stretching, peak at $1620 \mathrm{~cm}^{-1}$ which corresponds to the $\mathrm{NO}_{2}$ groups, peak at $1530 \mathrm{~cm}^{-1}$ which corresponds to nitrile compounds and a peak at $1443 \mathrm{~cm}^{-1}$ which corresponds to $\mathrm{CH}$ alkane group [13].

FTIR spectra of lyocell shows peaks at $3332 \mathrm{~cm}^{-1}$ which corresponds to the $-\mathrm{OH}$ stretching band of cellulose, peak at $2892 \mathrm{~cm}^{-1}$ which correspond to $\mathrm{CH}$ alkane group, and a peak at $1647 \mathrm{~cm}^{-1}$ which corresponds to the alkene group [13]. The functional groups shown by the FTIR spectra of these fabrics are characteristic and useful for comfort properties.

\subsection{Effect of silk/lyocell blend composition on thermophysiological comfort properties of fabrics}

The effect of silk/lyocell blend composition on thermophysiological comfort properties of fabrics such as air permeability, thermal resistance, water vapour permeability, absorbency and wickability are shown in Table 4. 
Table 4: Thermophysiological comfort properties of silk/lyocell blended fabrics

\begin{tabular}{|c|c|c|c|c|c|}
\hline PROPERTY & SAMPLES & MEAN & VARIANCE & $\begin{array}{l}\text { STANDARD } \\
\text { DEVIATION }\end{array}$ & $\begin{array}{c}\text { STANDARD } \\
\text { ERROR }\end{array}$ \\
\hline \multirow{5}{*}{$\begin{array}{l}\text { Air permeability } \\
\left(\mathrm{cm}^{3} / \mathrm{cm}^{2} / \mathrm{sec}\right)\end{array}$} & S 100 & 73.64 & 0.03 & 0.16 & 0.07 \\
\hline & S/L 75:25 & 124.55 & 2.90 & 1.49 & 0.66 \\
\hline & $\mathrm{S} / \mathrm{L} 50: 50$ & 134.55 & 4.14 & 1.76 & 0.78 \\
\hline & S/L 25:75 & 249.1 & 2.94 & 1.49 & 0.67 \\
\hline & L 100 & 275.16 & 2.95 & 1.49 & 0.67 \\
\hline \multirow{5}{*}{$\begin{array}{l}\text { Thermal resistance } \\
\left(\mathrm{m}^{2} \mathrm{~K} / \mathrm{W}\right)\end{array}$} & S 100 & 0.023 & 0.00 & 0.00 & 0.00 \\
\hline & S/L 75:25 & 0.018 & 0.00 & 0.00 & 0.00 \\
\hline & $\mathrm{S} / \mathrm{L} 50: 50$ & 0.018 & 0.00 & 0.00 & 0.00 \\
\hline & S/L 25:75 & 0.014 & 0.00 & 0.00 & 0.00 \\
\hline & L 100 & 0.014 & 0.00 & 0.00 & 0.00 \\
\hline \multirow{5}{*}{$\begin{array}{l}\text { Water vapour } \\
\text { permeability }\left(\mathrm{g} / \mathrm{m}^{2} /\right. \\
\text { day) }\end{array}$} & S 100 & 2038.15 & 3.33 & 1.58 & 0.71 \\
\hline & S/L 75:25 & 2043.22 & 3.09 & 1.54 & 0.69 \\
\hline & $\mathrm{S} / \mathrm{L} 50: 50$ & 2049.16 & 2.90 & 1.48 & 0.66 \\
\hline & $\mathrm{S} / \mathrm{L} 25: 75$ & 2056.28 & 3.11 & 1.55 & 0.69 \\
\hline & L 100 & 2064.97 & 3.35 & 1.59 & 0.71 \\
\hline \multirow{5}{*}{ Absorbency (sec) } & S 100 & 25 & 2.5 & 1.37 & 0.61 \\
\hline & $\mathrm{S} / \mathrm{L} 75: 25$ & 19.13 & 2.39 & 1.34 & 0.6 \\
\hline & S/L 50:50 & 15 & 3.33 & 1.58 & 0.71 \\
\hline & S/L 25:75 & 11.13 & 2.73 & 1.43 & 0.64 \\
\hline & L 100 & 7 & 0.83 & 0.79 & 0.35 \\
\hline \multirow{5}{*}{$\begin{array}{l}\text { Warp wickability } \\
(\mathrm{cm})\end{array}$} & S 100 & 2.5 & 0.01 & 0.1 & 0.05 \\
\hline & $\mathrm{S} / \mathrm{L} 75: 25$ & 2.8 & 0.03 & 0.16 & 0.07 \\
\hline & S/L 50:50 & 3.33 & 0.02 & 0.13 & 0.06 \\
\hline & S/L 25:75 & 3.48 & 0.03 & 0.15 & 0.07 \\
\hline & L 100 & 4.8 & 0.01 & 0.84 & 0.04 \\
\hline \multirow{5}{*}{ Weft wickability $(\mathrm{cm})$} & S 100 & 2.98 & 0.03 & 0.15 & 0.07 \\
\hline & $\mathrm{S} / \mathrm{L} 75: 25$ & 3.13 & 0.02 & 0.13 & 0.06 \\
\hline & $\mathrm{S} / \mathrm{L}$ 50:50 & 3.53 & 0.01 & 0.08 & 0.04 \\
\hline & S/L 25:75 & 4.69 & 0.03 & 0.14 & 0.06 \\
\hline & L 100 & 5.25 & 0.02 & 0.11 & 0.05 \\
\hline
\end{tabular}

\subsubsection{Air permeability}

One of the comfort measures that greatly affect the wearer is air permeability. A material that is permeable to air is likely to be permeable to water, but very often may result in physical and psychological discomfort to the wearer. An increase in air permeability of the fabric implies that more air will be able to penetrate through the fabric, which will enhance heat and vapour transfer. Hence, a fabric with high air permeability implies a more open structure which will give a cooler perception to the wearer in comparison to a less permeable fabric [1]. Expectedly, L100 possesses appreciably higher air permeability than the blended fabrics and the $100 \%$ silk fabric and the air permeability increases with the increase in lyocell content of the silk/lyocell blended fabric as shown in Table 4.

Table 5 shows the statistical analysis of air permeability which is found to be significantly different between the silk/ lyocell blend compositions at $5 \%$ significant level. The $\mathrm{F}_{\text {actual }}(11587.31)$ value is found to greater than $\mathrm{F}_{\text {critical }}$ value (3.055). Silk does not give positive results in air permeability because it has a very high cohesivity and adhesivity [14]. 
Table 5: One-way ANOVA of silk/lyocell blended fabrics

\begin{tabular}{l|c|c|c|c|c|c}
\hline $\begin{array}{l}\text { SOURCE OF } \\
\text { VARIATION }\end{array}$ & $\begin{array}{c}\text { SUM OF } \\
\text { SQUARE } \\
\text { VALUE (SS) }\end{array}$ & $\begin{array}{c}\text { DEGREE OF } \\
\text { FREEDOM } \\
(\mathbf{d f})\end{array}$ & $\begin{array}{c}\text { MEAN } \\
\text { SQUARE } \\
\text { VALUE (MS) }\end{array}$ & $\begin{array}{c}\text { F ACTUAL } \\
\left(\mathbf{F}_{\text {actual }}\right)\end{array}$ & $\begin{array}{c}\text { F CRITICAL } \\
\left(\mathbf{F}_{\text {critical }}\right)\end{array}$ & $\begin{array}{c}\text { P VALUE } \\
(\mathbf{p})\end{array}$ \\
\hline $\begin{array}{l}\text { Air permeability } \\
\left(\mathrm{cm}^{3} / \mathrm{cm}^{2} / \mathrm{sec}\right)\end{array}$ & 120154.16 & 4 & 30038.54 & 11587.31 & 3.055 & $5.67027 \mathrm{E}-26$ \\
\hline $\begin{array}{l}\text { Thermal resistance } \\
\left(\mathrm{m}^{2} \mathrm{~K} / \mathrm{W}\right)\end{array}$ & 0.00 & 4 & $3.68016 \mathrm{E}-05$ & 46.372 & 2.866 & $7.64736 \mathrm{E}-10$ \\
\hline $\begin{array}{l}\text { Water vapour permeabili- } \\
\text { ty }\left(\mathrm{g} / \mathrm{m}^{2} / \text { day }\right)\end{array}$ & 1809.61 & 4 & 452.403 & 143.332 & 3.055 & $9.29125 \mathrm{E}-12$ \\
\hline Absorbency $(\mathrm{sec})$ & 780.08 & 4 & 195.0187 & 82.693 & 3.056 & $4.9228 \mathrm{E}-10$ \\
\hline Warp wickability $(\mathrm{cm})$ & 12.56 & 4 & 3.139 & 149.488 & 3.055 & $6.8379 \mathrm{E}-12$ \\
\hline Weft wickability $(\mathrm{cm})$ & 16.16 & 4 & 4.038 & 192.703 & $1.06616 \mathrm{E}-12$ & 3.055568276 \\
\hline Drape $(\%)$ & 208.72 & 4 & 52.179 & 104.462 & 3.055 & $9.20602 \mathrm{E}-11$ \\
\hline Warp crease recovery $\left(^{\circ}\right)$ & 200.7 & 4 & 50.175 & 18.845 & 3.056 & $1.02514 \mathrm{E}-05$ \\
\hline Weft crease recovery $\left(^{\circ}\right)$ & 355.18 & 4 & 88.793 & 32.436 & 3.056 & $3.19114 \mathrm{E}-07$ \\
\hline $\begin{array}{l}\text { Warp bending length } \\
(\mathrm{cm})\end{array}$ & 0.45 & 4 & 0.1135 & 383.248 & 3.055 & $6.65428 \mathrm{E}-15$ \\
\hline Weft bending length $\left(\mathrm{cm}^{\circ}\right)$ & 0.37 & 4 & 0.0925 & 351.408 & 3.055 & $1.26597 \mathrm{E}-14$ \\
\hline
\end{tabular}

\subsubsection{Thermal resistance}

Thermal properties are expressed as amount of heat transmission through the thickness of the fabric in a given surface area. Thermal resistance values can be considered as one of the most important thermal insulation properties of fabrics as it indicates the air trapped into the fabric between the fibers and yarns [15]. Table 4 depicts the mean values of thermal resistance for silk/lyocell blended fabrics. Thermal resistance is found to be very good for $100 \%$ silk fabrics and lowest for $100 \%$ lyocell fabrics. The thermal resistance of the fabrics has a significant difference at $5 \%$ level with respect to blend proportions with $\mathrm{F}_{\text {actual }}$ being 46.372 in comparison with $\mathrm{F}_{\text {critical }}(2.866)$ with a degree of freedom of 4 . It is also found that thermal resistance showed a decrease with increase in air permeability for silk/lyocell blended fabrics.

\subsubsection{Water vapour permeability}

Water vapour permeability is one of the important properties of thermal comfort that determines the capability of transporting perspiration through a textile material [15]. Water vapour permeability of silk/lyocell blended fabrics (Table 4) gradually increases as the percentage of lyocell increases in the blend composition with L100 having the highest value and S100 has the lowest value. The water vapor permeability values are found to be statistically significant between the blend compositions $\left[\mathrm{F}_{\text {actual }}=143.332>\mathrm{F}_{\text {critical }}=3.055(\mathrm{p}<0.05)\right]$.

The air permeability of blended fabrics was correlated with water vapour permeability using the Pearson's correlation coefficient as seen in Figure 2. A clear linear relationship was observed between air permeability and water vapour permeability of the fabric with Pearson's correlation coefficient value of ' $r$ ' being 0.9355 indicating a strong positive correlation. As the air permeability of the fabric increases, the water vapour permeability also increases which shows that they are directly related to each other. 


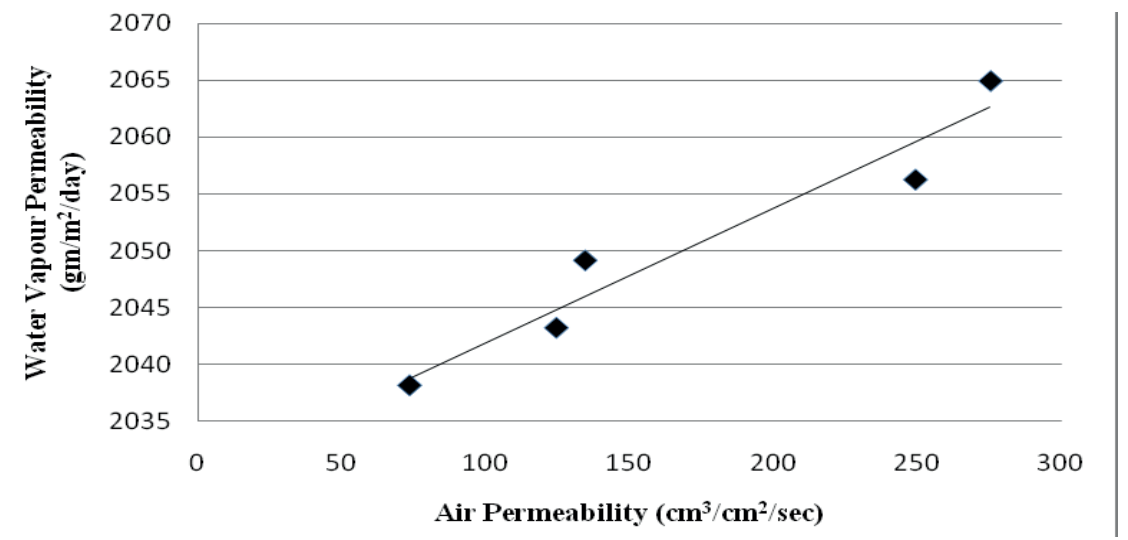

Figure 2: Relationship between air permeability and water vapour permeability of silk/lyocell blended fabrics

\subsubsection{Absorbency}

The ability of the fabric to absorb water is tabulated in Table 4 . The absorption of water on any material increases when the resistance to water flow decreases [16]. The absorbency values of silk/lyocell blended fabrics reveal that with the increase in lyocell content in silk/lyocell blended fabrics, the absorbency also increases. The absorbency decreases in the following order: $\mathrm{L} 100>\mathrm{S} / \mathrm{L} 25: 75>\mathrm{S} / \mathrm{L}$ 50:50 $>\mathrm{S} / \mathrm{L}$ 75:25 $>\mathrm{S}$ 100. ANOVA results show that there is a significant difference among the silk/lyocell blend compositions $\left[\mathrm{F}_{\text {actual }}=82.693>\mathrm{F}_{\text {critical }}=3.056(\mathrm{p}<0.05)\right]$.

\subsubsection{Wickability}

Wickability is also an important factor in determining the comfort of clothing. Wicking can take place either around the body to allow a greater area for evaporation or through the fabric away from the skin [15]. High wickability facilitates quick drying and fast cooling in hot environments [17]. Table 4 shows the mean values of wickability on silk/lyocell blended fabrics. It is evident that as the proportion of lyocell increases in the silk/lyocell blended fabrics, the wickability also increases in the warp as well as weft directions. The reason may be attributed to the availability of more air spaces in the fabric as evident from higher values of air permeability. There is a significant difference $(\mathrm{p}<0.05)$ in the wickability of silk/lyocell blended fabrics in the warp $\left[\mathrm{F}_{\text {actual }}=149.488>\mathrm{F}_{\text {critical }}=3.055\right]$ as well as weft $\left[\mathrm{F}_{\text {actual }}=192.703>\mathrm{F}_{\text {critical }}=0.000\right]$ directions.

\subsection{Effect of silk/lyocell blend composition on tactile comfort properties of fabrics}

The effect of silk/lyocell blend composition on tactile comfort properties of fabrics such as drape, crease recovery and bending length are shown in Table 6.

Table 6: Tactile properties of silk/lyocell blended fabrics

\begin{tabular}{l|c|c|c|c|c}
\hline \multirow{2}{*}{ PROPERTY } & SAMPLES & MEAN & VARIANCE & $\begin{array}{c}\text { STANDARD } \\
\text { DEVIATION }\end{array}$ & $\begin{array}{c}\text { STANDARD } \\
\text { ERROR }\end{array}$ \\
\hline \multirow{5}{*}{ Drape (\%) } & S 100 & 64.88 & 0.73 & 1.04 & 0.46 \\
\cline { 2 - 6 } & S/L 75:25 & 68.15 & 1.20 & 1.02 & 0.46 \\
\cline { 2 - 6 } & S/L 50:50 & 66.56 & 0.19 & 0.53 & 0.24 \\
\cline { 2 - 6 } & S/L 25:75 & 61.6 & 0.22 & 0.44 & 0.19 \\
\cline { 2 - 6 } & L 100 & 59.33 & 0.16 & 0.46 & 0.20 \\
\hline \multirow{5}{*}{ Warp crease recovery $\left(^{\circ}\right)$} & S 100 & 132.25 & 2.91 & 1.48 & 0.66 \\
\cline { 2 - 6 } & S/L 75:25 & 134.75 & 3.08 & 1.53 & 0.68 \\
\cline { 2 - 6 } & S/L 50:50 & 136 & 3.33 & 1.58 & 0.71 \\
\cline { 2 - 6 } & S/L 25:75 & 139.25 & 2.25 & 1.30 & 0.58 \\
\cline { 2 - 6 } & L 100 & 141.13 & 1.73 & 1.14 & 0.51 \\
\hline
\end{tabular}




\begin{tabular}{|c|c|c|c|c|c|}
\hline \multirow{5}{*}{ Weft crease recovery $\left(^{\circ}\right)$} & S 100 & 130 & 3.33 & 1.58 & 0.71 \\
\hline & $\mathrm{S} / \mathrm{L} 75: 25$ & 130.88 & 2.06 & 1.25 & 0.56 \\
\hline & S/L 50:50 & 134.38 & 1.56 & 1.10 & 0.49 \\
\hline & S/L 25:75 & 135.5 & 3 & 1.52 & 0.68 \\
\hline & L 100 & 141.88 & 3.72 & 1.67 & 0.75 \\
\hline \multirow{5}{*}{ Warp bending length $(\mathrm{cm})$} & S 100 & 1.56 & 0.00 & 0.02 & 0.01 \\
\hline & S/L 75:25 & 1.26 & 0.00 & 0.01 & 0.01 \\
\hline & S/L 50:50 & 1.21 & 0.00 & 0.01 & 0.01 \\
\hline & S/L 25:75 & 1.18 & 0.00 & 0.01 & 0.01 \\
\hline & L 100 & 1.14 & 0.00 & 0.01 & 0.01 \\
\hline \multirow{5}{*}{ Weft bending length $(\mathrm{cm})$} & S 100 & 1.62 & 0.00 & 0.01 & 0.01 \\
\hline & S/L 75:25 & 1.53 & 0.00 & 0.02 & 0.01 \\
\hline & S/L 50:50 & 1.41 & 0.00 & 0.02 & 0.01 \\
\hline & $\mathrm{S} / \mathrm{L} 25: 75$ & 1.33 & 0.00 & 0.01 & 0.01 \\
\hline & L 100 & 1.24 & 0.00 & 0.02 & 0.01 \\
\hline
\end{tabular}

\subsubsection{Drape}

Drape is the term used to describe the way a fabric hangs under its own weight. It is one of the most important fabric characteristics since it shows how good a garment looks in use [15]. Table 6 shows that drape is better for 100\% lyocell fabrics when compared to $100 \%$ silk fabrics. Drape percentage decreases in the following order: S 100 $>$ S/L 25:75 > S/L 50:50 > S/L 75:25 > L 100, thereby implying that as the percentage of lyocell increases, drape of the blended fabrics also becomes better. ANOVA results from Table 5 reveal that silk/lyocell blend compositions have a significant difference on drape $\left[\mathrm{F}_{\text {actual }}=104.462>\mathrm{F}_{\text {critical }}=3.055(\mathrm{p}<0.05)\right]$.

\subsubsection{Crease recovery}

The mean crease recovery angles in warp and weft directions for various silk/lyocell blended fabrics are given in Table 6 . Formation of creases in the fabric and recovery there form is largely dependent on the properties of the constituent fibers. Therefore, the effect of blend composition on creasing behaviour was analyzed. It is observed that irrespective of the blend composition, warp crease recovery angle is slightly higher than weft crease recovery angle. Crease recovery is very good in the case of $100 \%$ lyocell as compared to $100 \%$ silk and is found to increase with an increase in the lyocell content of the blended fabrics. The crease recovery values are found to be significant between the blend compositions as seen in Table 5 for warp $\left[\mathrm{F}_{\text {actual }}=18.845>\mathrm{F}_{\text {critical }}=3.056(\mathrm{p}<0.05)\right]$ as well as weft $\left[\mathrm{F}_{\text {actual }}=32.436>\mathrm{F}_{\text {critical }}=3.056(\mathrm{p}<0.05)\right]$ directions.

\subsubsection{Bending length}

Bending length is a measure of softness. It is observed from Table 6 that the mean bending length values decreases with increasing lyocell content in the silk/lyocell blended fabrics indicating that softness of the fabric increases with increase in the lyocell percentage. Bending length for 100\% lyocell fabrics is found to be 1.14 and 1.24 and for $100 \%$ silk it is found to be 1.56 and 1.62 for warp and weft respectively. The bending length values as seen in Table 5 are found to be significant $(\mathrm{p}<0.05)$ between the silk/lyocell blend compositions for warp $\left[\mathrm{F}_{\text {actual }}=383.248>\mathrm{F}_{\text {critical }}=3.055\right]$ as well as weft $\left[\mathrm{F}_{\text {actual }}=\right.$ $\left.351.408>\mathrm{F}_{\text {critical }}=3.055\right]$.

\section{CONCLUSIONS}

There has been an on-going effort into work on silk/lyocell blended fabrics. This study is a continuation of this effort. Following conclusions are drawn from the study conducted to assess the effects of silk/lyocell blend compositions on thermophysiological and tactile comfort properties of fabrics. Characterization of $100 \%$ silk, $25 \%$ silk \& $75 \%$ lyocell and $100 \%$ lyocell fabrics by FTIR showed peaks pertaining to the functional groups corresponding to the respective fabrics and confirm the silk/lyocell blend compositions. Air permeability was found to be high for lyocell-rich blends. With respect to thermal resistance, the fabrics containing silk showed a higher value in comparison with lyocell-rich blends. Water vapour permeability, absorbency and wickability for lyocell and lyocell-rich blends are found to be superior as compared to $100 \%$ silk fabrics. Drape of the lyocell rich fabrics is good in comparison with $100 \%$ silk fabrics. Crease recovery is also found 
to be good for lyocell rich blends in comparison with $100 \%$ silk fabrics. The fabrics containing $25 \%$ silk and $75 \%$ lyocell showed very good properties for comfort. The present study clearly showed that by an assessment of properties that are necessary to get the best comfort levels, it is possible to engineer a fabric by appropriately choosing silk and lyocell combination for fabric constructional parameters based on their established relationships with different comfort parameters. The cost of lyocell is nearly one third of silk and therefore, blending silk and lyocell will merge the richness of silk and softness of lyocell and give a techno-economic edge over other fabrics in the textile industry.

\section{BIBLIOGRAPHY}

[1] RAJ, S., SREENIVASAN, S., "Total wear comfort index as an objective parameter for characterization of overall wearability of cotton fabrics", Journal of Engineered Fibre and Fabrics, v. 4, pp. 29-41, 2009.

[2] GAHLOT, M., PANT S., "Properties of oak tasar/viscose blended yarns", Indian Journal of Fibre and Textile Research, v. 36, pp. 187-189, June 2011.

[3] CHAKRABORTY, A., SAHA, P. K., SINGHA, K., et al."Application of synthesized disperse-azo dyes on silk fabric - a new vista of silk dyeing", Journal of the Textile Association, 229, Nov. 2011.

[4] GHAREHAGHAJI, A. A., ZADHOOSH, A., KHODABAKHSH, M. N., "Study on the mechanical damage of lyocell fibers in ring and rotor yarn spinning”, In: Proceedings of seventh International Conference: TEXCI, pp. 1-6, 2010.

[5] PRAMANIK, P., PATIL, V. M., "Low stress mechanical behaviour of fabrics obtained from different types of cotton/ nylon sheath/core yarn”, Indian Journal of Fibre and Textile Research, v. 34, pp. 155-161, June 2009.

[6] TYAGI, G. K., GOYAL, A., CHATTOPADHYAY, R., "Physical characteristics of tencel-polyester and tencel-cotton yarns produced on ring, rotor and air-jet spinning machines", Indian Journal of Fibre and Textile Research, v. 38, pp. 230236, Sep. 2013.

[7] JEYARAJ, M. J., ARUMUGAM, M., KULANDAIAPPAN V., "A study on silk and its mixed fabric for functional properties”, Walailak Journal of Science and Technology, v. 13, pp. 913-922, 2016.

[8] VIJAYAKUMAR, H, L., MURALIDHAR, J. S., http://www.fiber2fashion.com/industry-article/9/850/design-anddevelopment-of-an-equipment-to-measure-the-hand-value-of-apparel-fabric7.asp. Accessed in August 2007.

[9] JOSHI, H. D., JOSHI, D. H., PATEL, M. G., "Dyeing and finishing of lyocell union fabrics: an industrial study", Coloration Technology, v. 126, pp. 194-200, Sep. 2010.

[10] BEHERA, B. K., SARDANA, A., VERMA, B. C., "Studies on polypropylene - cotton spun yarns and their fabrics", Indian Journal of Fibre and Textile Research, v. 26, pp. 280-286, Sep. 2001.

[11] RAMAIAH, G., RADHALAKSHMI, Y. C., NACHANE, R. P.,http://www.fiber2fashion.com/industry-article/38/3739/ comparative-analysis-of-lowstress-mechanical properties1.asp. Accessed in Nov. 2012.

[12] ZHANG, X. M., WYETH, P., "FTIR spectroscopy to detect sericin on historic silk”, Science China Chemistry, v. 53, pp. 626-631, March 2010.

[13] DYAKONOV, T., YANG, C. H., BUSH, D.,et al."Design and characterization of a silk-fibroin-based drug delivery platform using naproxen as a model drug”, Journal of Drug Delivery, v. 2012, pp. 1-10, 2012.

[14] BEHERA, B. K., MISHRA, R., "Effect of crease behaviour, drape and formability on appearance of light weight worsted suiting fabrics", Indian Journal of Fibre and Textile Research, v. 32, pp. 319-325, Sep. 2007.

[15] SONG, G., Improving comfort in clothing, 1 ed., Cambridge, Woodhead Publishing, 2011.

[16] SAMPATH, M. B., SENTHILKUMAR, S., "Effect of moisture management finish on comfort characteristics of microdenier polyester knitted fabrics", Journal of Industrial Textiles, v. 39, pp. 163-173, Oct. 2009.

[17] TYAGI, G. K., KRISHNA, G., BHATTACHARYA, S., et al. "Comfort aspects of finished polyester-cotton and polyester-viscose ring and MJS yarn fabrics”, Indian Journal of Fibre and Textile Research, v. 34, pp. 137-143, June 2009.

\section{ORCID}

Mariyam Adnan

Jeyakodi Moses https://orcid.org/0000-0002-8327-2751

https://orcid.org/0000-0002-9530-8731 